\title{
O ESPÍRITO DO NOSSO TEMPO:
}

\author{
O presente crucificado
}

por Norval Baitello Junior ${ }^{1}$

Resumo/Abstract: $O$ desenvolvimento da cultura humana caminhou a trilha do mais concreto - a cultura da terra - para o mais abstrato, a cultura do ar, sob a forma do espírito. A hipertrofia da cultura do espírito tem trazido distúrbios na capacidade vinculadora do homem, tais quais a perda do presente e a fuga para o passado ou para o futuro. Ao mesmo tempo, a cisão entre as duas culturas gerou a auto-referência no domíno de ambas, produzindo dosi tipos distintos de fundamentalismo: a assepsia e a exatidao, por um lado, a negacao dos corpos, por outro. Com isso, o espírito do nosso tempo gera um tempo em quiasma, crucificado, produzindo ofuscamento e narcose.

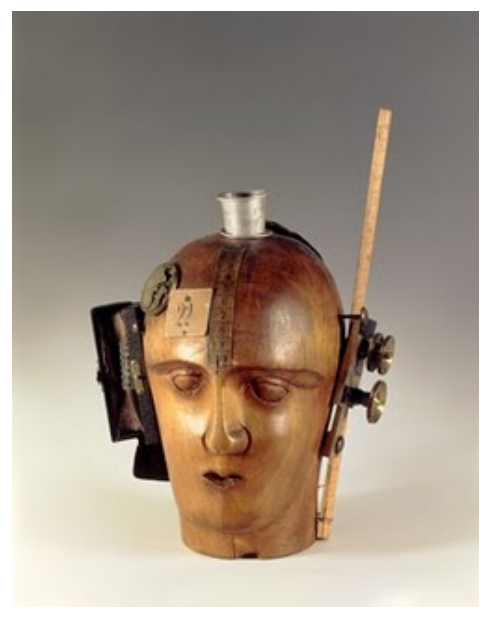

Cabeça Mecânica Autor: Raoul Hausman,1919-ALE

\footnotetext{
${ }^{1}$ Norval Baitello Junior é doutor em Ciências da Comunicação pela Universidade Livre de Berlim, professor da Pós-Graduação em Comunicação e Semiótica da PUC/SP.
} 


\section{A "Cabeça Mecânica"}

Quando Raoul Hausman em 1919 criou sua "Cabeça Mecânica", também denominada por ele de "Espírito do Nosso Tempo", mal podia imaginar a extensão da era que apenas se configurava ali nos alegres (nem por isso menos sangrentos) anos das grandiosas e fracassadas utopias. Não me refiro aqui àqueles projetos políticos mais visíveis e portanto mais evidentes que pautaram o século XX. Eles foram apenas desdobramento visível dos grandes projetos invisíveis que corriam nos subterrâneos e nas artérias do tempo. A grande utopia, com sua inevitável grandiosidade e seu destino também inevitável ao fracasso, era mais profunda, abrangente e destrutiva e respondia pelo nome de 'espírito'.

Vamos, pois, buscar compreender melhor o que é essa configuração cultural que ditou sentidos e rumos, direções e projetos, tipos de codificação e maneiras de comunicação e a incomunicação do nosso tempo .

"Spiritus", em latim, quer dizer 'sopro, vento, hálito, respiração, exalação'. Apenas em sentido figurado é que a palavra ganha os significados de 'sopro divino, espírito criador, sentimento (ira, cólera, arrogância, orgulho, presunção) e alma'. A associação do aéreo com o invisível possui um componente espacial e uma marca de materialidade. A questão da espacialidade: o novo e surpreendente está no alto e o caminho para ele é o percurso da vertical. E sua materialidade é diáfana e invisível aos olhos, mas sensível à pele, ao olfato e, sobretudo, às ocultas entranhas dos órgãos superiores da respiração e às profundezas dos também invisíveis pulmões. Assim, somente é possível sentir o 'espírito', nunca vê-lo. E senti-lo significa incorporá-lo, aspirá-lo para dentro do corpo.

Gernot e Hartmut Böhme assim escrevem a respeito do ar: "El aire es el elemento invisible. Es invisible, intangible, en él no hay ninguna orientación. Somos seres aéreos. 
Pero, a diferencia de las aves, no podemos movernos libremente en el aire; más bien, estamos atados a la tierra y precisamos de ella para nuestra estabilidad y para orientarnos.

Para poder hacer tangible al aire hay que hacerlo visible, por ejemplo mediante el humo, una bandera o una vela. Solo se le puede sentir como viento. "(Böhme, G. y H., Fuego, Agua, Tierra, Aire. Una historia cultural de los elementos. Barcelona: Herder, 1998).

\section{O sopro da criação: mito e técnica}

O barro e o sopro são a origem da vida segundo os mitos judaico-cristãos de criação. 0 barro, vindo do elemento mitologicamente feminino, da grande mãe-terra, junta-se ao elemento vindo do grande pai por meio do ar de seu sopro que injeta ou insufla o 'espírito'na matéria.

Segundo o mito hebraico, Deus criou o homem (em hebraico "adam") de barro (em hebraico "adamah") e nele injetou seu sopro (em hebr. "ruach"). Tanto o hebraico "ruach", quanto a palavra grega "pneuma" quanto a latina "spiritus" significam primordialmente 'hálito, sopro, vento' e, somente derivadamente, também significam 'espírito'. A palavra alemã "Odem", variante poética e teológica de "Atem", 'respiração' é usada como 'sopro' (divino). Assim, a palavra alemã "Geist", como a inglesa "ghost", 'espírito', procedem ambas do indo-europeu "gheisd-", com o sentido provável de 'estar fora de si, fora do corpo'. Assim, a associação do ar com a vida animada como algo invisível e diáfano, está registrada na etimologia de diferentes palavras para 'espírito'.

Contudo, o mais notável uso da força e da energia presentes no ar foi descoberto pela técnica e pela ciência no desenvolvimento e no domínio das máquinas a vapor. Era o aprisionamento do vento, um tipo de vento engarrafado, executando controladamente o 
trabalho do vento livre e voluntarioso que soprava quando queria, como queria, para onde e com a intensidade que quisesse. A força dos furacões e vendavais estava domesticada. Descobriu-se, com a técnica do vapor, a produção artificial do espírito. Com sua força inestimável ele se tornava então passível de aprisionamento e domesticação.

Paralelamente desenvolveu-se a técnica oposta, a descoberta e a produção do vazio, do vácuo, vale dizer, do nada. Blaise Pascal fez experimentos em 1647/48 com a rarefação do ar, aproximando-se do nada. Mas quem, poucos anos depois, em 1654, conseguiu encher um recipiente com o nada e provou a imbatível força do não-ar, foi o burgomestre de Magdeburgo, Otto von Guericke. Sua irrefutável demonstração reuniu duas semiesferas de cobre, uma bomba de retirada do ar de seu interior, e cavalos puxando de ambos os lados. A força dos cavalos não conseguiu separar as semiesferas cheias de nada. (Cf. Roters 1990:23).

Não por acaso, a grande polêmica metafísica da época de von Guericke - que ele evidentemente acompanhava em suas muitas viagens - versava sobre Deus e o nada. Um partido defendia a opinião segundo a qual a existência de Deus não permite, exclui o nada, não deixa vazio; o outro, ao contrário, afirmava que a existência de Deus inclui a existência do nada. O burgomestre levou a polêmica - um movimento do ar, uma pura ação do espírito - às últimas conseqüências, transportando-a ao universo da técnica - ao reino da terra -.

Eberhard Roters escreve a respeito do nada: "Do ponto de vista da história da consciência deixa-se verificar com facilidade que o Nada não é algo como uma quimera metafísica, mas um objeto palpável e sensorialmente cognoscível, uma coisa, ou, se assim se quer, uma não-coisa."(Roters 1990:20). 


\section{As duas culturas: a da terra e a do ar}

A rigor, a palavra cultura está, por um lado, em sua acepção mais arcaica, radicalmente associada com o barro e a terra, portanto associada à sedentarização do homem. O verbo latino "colo" ("colere"), particípio passado "cultum", significa em primeira instância,'habitar, morar'(tal significado continua presente nas palavras 'silvícola', 'arborícola', etc), e depois 'cultivar (sent. físico e moral)'. Assim, a palavra latina "cultura", em seu primeiro e concreto significado remete à terra como lugar de moradia e lugar de cultivo, refere-se portanto à agricultura. Nesse espaço desenvolvem-se os infindáveis prolongamentos do corpo humano sob a forma de instrumentos e ferramentas, de sistemas instrumentais complexos, que exigem aprendizagem e domínio, aqui se desenvolve o universo da técnica.

Por outro lado, há uma mudança de foco na essência da palavra, quando ela, no sentido figurado, é usada como 'cultura do espírito'. Há aí um deslocamento da cultura concreta e palpável do elemento terra, para uma cultura construída imaterialmente, a princípio invisível, do espírito e do sopro inoculado, para o elemento ar. Por serem invisíveis, seus sinais necessitam sempre um portador material, um suporte, um meio, uma mediação que os veiculem. Necessitam, assim, os materiais da terra para incorporar os valores e teores abstratos e intangíveis do espírito, do sopro. Assim como o barro precisa do hálito para animar-se, o sopro necessita da matéria tangível para manifestar sua vida. Igual processo sucede com a cultura em sua segunda acepção: todos os artefatos materiais carecerão de sentido se eles não se colocarem a serviço de uma projeção no tempo, de uma meta, de uma finalidade dada pelo espírito. Assim também as manifestações do espírito não poderão prescindir os suportes materiais para sua manifestação. 
Tal simbiose permite enxergar os sistemas codificadores da cultura humana como reino do espírito, como segunda realidade (I. Bystrina). Mas a segunda realidade, social e cultural, é visceralmente plantada na primeira realidade, biossocial. E as duas interagem reciprocamente, em dupla mão de direção.

\section{A cisão entre as duas culturas: a síndrome da auto-referência}

Se, por um lado, a cultura em sua concepção 'terra' produz o cultivo do entorno, para torna-lo habitável, para apropriar-se dele, para domesticar o mundo, por outro lado, a presença das imagens internas voláteis no sonho e nas múltiplas linguagens dele derivadas - jogos, estados alterados de consciência (I. Bystrina), devaneios, sonhos diurnos (E. Bloch), simulações e construção de cenários futurológicos - aponta para a construção de um mundo de imagens "aéreas", um mundo do "espírito", povoado de símbolos, textos, histórias, figuras e sistemas elaborados. O conceito de humano se amplia, com a segunda realidade, para "sapiens-demens" (Morin).

A primeira e original cultura, instrumental e domesticadora do entorno, cuida de desenvolver os meios materiais de apropriação do espaço e do tempo do homem, criando sistemas de crescente complexidade e eficiência para intervir sobre todos os sistemas naturais com os quais interagimos ou dos quais dependemos. A segunda atua em nível simbólico, criando seres de "ar" e conferindo a eles o sopro da vida, seres diáfanos, sim, mas tão reais quanto nossa própria existência no espaço-tempo.

O entrelaçamento entre as ferramentas da cultura-terra (com todos seus textos instrumentais) e a cultura-ar, com suas crenças e seus seres de imaginação, é profundo e suas fronteiras são fluidas e móveis. Tal mobilidade e fluidez não conseguiram impedir, no entanto, que o espírito dual do nosso tempo (um espírito de 'diabalein') as cindisse, 
insuflando em cada uma delas a soberba da auto-referência. Os fundamentalismos não são outra coisa que a exacerbação da auto-referência. Quando os fundamentalismos imperam na "primeira realidade", produzem a exacerbação da assepsia e da exatidão, fantasias próprias do mundo das máquinas, dos mecanismos, da técnica autocentrada e da ciência voltada para si mesma. É quando as máquinas sonham que são deuses (Kamper 1997:63).

E quando os fundamentalismos imperam na 'segunda realidade', temos a negação dos corpos e sua existência complexa (biofísica, psíquica, social, comunicacional, cultural).

Em ambos os casos a grande lesão que se produz recai sobre os sistemas de vínculos, entre o homem e seu semelhante, entre o homem e si mesmo, entre o homem e seu presente, entre o homem e sua história, seu passado ou seu futuro.

\section{As utopias da religação original}

A saudade e a impaciência são sentimentos do ar, invisíveis, provocados pela perda do presente. As doenças da saudade e da impaciência, uma na busca pelo passado, outra em busca do futuro, provocam movimentos desordenados nas duas direções opostas (já que no ar não há nenhuma orientação), mas ambos associados com a falta do ar, o que equivale a uma falta de canal com o invisível que está dentro, um tipo de perda cultural da propriocepção.

Toda falta exige um signo para sinalizá-la como ausência, fazê-la visível. A busca do passado e o culto da memória que buscam compensar a perda do presente geram os signos acústicos e os sons enlouquecidos que produzem nossos artefatos e máquinas, recordando e exacerbando a tagarelice da nossa fala e gerando o ruído branco de nossas cidades. Da oralidade dos relatos à "oralidade" dos artefatos, eis o caminho trilhado para 
recordar os corpos perdidos com a perda do presente. "Recordar" possui em seu âmago a palavra "coração".

Já os signos da impaciência se manifestam na fumaça e seus desdobramentos imagéticos que preenchem toda a nossa atmosfera, sinalizando a febril atividade que nos levará ao futuro. O ansioso e impaciente progresso tem, portanto, duas faces para o espírito do nosso tempo, uma de ininterruptas sonoridades, outra de onipresente fumaça. Ambas sublinham o vazio do presente que nos foi roubado, pelos artifícios exacerbados da simulação, dos signos de presente, de um presente in effigie, o retrato de um morto. A cinzenta fumaça e o ruído branco são as duas formas que encontra o homem para preencher o vazio de um espírito que, feito de ar, portanto, invisível, nos impele para o nada, para o não-corpo (Kamper), para as não-coisas (Flusser). E, aquilo que, na primeira revolução industrial constrói as chaminés e produz a fumaça, grandes ícones do "verticalismo e da conquista de campos simbólicos (Pross), transforma-se, na terceira revolução industrial, em imagens em profusão, imagens onipresentes como a fumaça. As imagens que, geradas pela fumaça, esfumaçam também a visão e a sensação, sobrecarregam os olhos diante da superexposição (levando afinal a que não mais vejam nada) e comprometem ainda mais a propriocepção por meio do excesso de superfícies e superficialidades estranhas ao corpo.

\section{O tempo-cabeça ou o tempo de nosso espírito: ofuscamento e narcose}

A Cabeça Mecânica de Raoul Hausmann é uma cabeça sem corpo. Seu corpo é invisível como o espírito, um "corpus absconditum"(Dietmar Kamper). E, como é oculto, somente pode ser imaginado, jamais visto. Por isso, o tempo-cabeça, como a Cabeça Mecânica de Hausmann, tem olhos opacos e rígidos, duplamente cegos, não enxergam e não se deixam ver, não se oferecem como janelas de um espírito que há tempos se perdeu na auto- 
referência. $\mathrm{O}$ excesso de imagens do espírito a serviço da ferramenta (a régua, o miolo de um relógio, um carimbo numérico, o copo dobrável portátil, fruto de uma engenharia construtora de objetos industriais) deixa cego o espírito que respira. Seus olhos olham para dentro, perpetrando a ruptura dos vínculos com o exterior. E a cabeça mecânica se torna o ícone de um tempo-cabeça, a antecipadora de um espírito paradoxal, uma estrutura em quiasma, conforme o revela Kamper, evocando Merleau-Ponty: "Quiasma: Meu corpo - as coisas realizadas pela duplicação do meu corpo em dentro e fora - e a duplicação das coisas (seu dentro e seu fora). Com base nessas duas duplicações é possível: a colocação do mundo entre duas páginas do meu corpo; a colocação do meu corpo entre duas páginas de cada uma das coisas e do mundo". (Apud Kamper, 1997:77).

As imagens, originalmente um produto do espírito, reservado para seu alimento interior, tornam-se ferramentas a serviço do mais externo dos mundos, o mundo das superfícies. Por isso são possíveis as inversões em forma de cruz: corpo e coisas são páginas que se entrecruzam, mas páginas opacas, que não permitem ao espírito entrar em suas linhas, em suas profundezas. Diante da opacidade, só nos resta tornarmo-nos opacos, diante das superfícies igualmente se nos reserva apenas a alternativa da superficialidade. Assim, toda estrutura em cruz inverte papeis e funções duplamente: os olhos servem para não ver, o corpo serve para não sentir, as imagens servem para ofuscar, as sensações servem para narcotizar.

\section{Cumulatividade e retroatividade, arqueologias e futurologias:}

\section{\&nbspo tempo em quiasma}

Desde sempre a cultura humana, por sua dupla natureza, de memória e de sonho, se construiu paradoxalmente. Regida pela lei da cumulatividade, sobrepõe imagens e textos 
sobre os já existentes de maneira a fazer as camadas arcaicas transparecerem sempre na face das novas. A cumulatividade não soterra o passado, mas o resgata, arqueologicamente. Igualmente regida pela lei da retroatividade, a cultura projeta sobre todo o seu corpus ou acervo, aquilo que futurologicamente encena, sonha, idealiza, deseja, anseia. Assim, a cultura é paradoxal porque nela o arcaico se projeta no futuro e o futuro se "retrojeta" sobre todo o arcaico, inseminando toda a memória com o sonho e os projetos e inseminando igualmente os sonhos com matrizes arcaicas.

Disse Flusser que já não somos "subjetos"(sujeitos) mas projetos. O espírito de nosso tempo inverteu em cruz a natureza-terra da primeira realidade, transformando-a em virtualidade supressora de toda existência física. As não-coisas avançam sobre os espaços das coisas. Primeira vítima: os corpos vivos. E inverteu a natureza-ar da segunda realidade, transformando-a em mecanismo. A segunda realidade, contaminada de causalidades e mecânicas, suga para o império do ar a matéria suprimida das não-coisas. As coisas passam a viver apenas no mundo das não-coisas, tal qual as não-coisas passam a povoar o mundo das coisas. Tal o quiasma do espírito do nosso tempo: materializar o imaterial e desmaterializar a matéria.

Ora, matéria vem de "materia", em latim, que significa 'madeira' (tal qual a Cabeça Mecânica de Hausmann), que por sua vez, procede do indo-europeu "mater", composto do sufixo "-ter" (relação de parentesco) e da raiz "ma-", com três grandes núcleos semânticos. "Ma-"significa: a) bom, b) mãe, c) úmido. Da associação desses três universos nasce a comunicação humana primordial, como gênese dos vínculos. Em algum momento o espírito do nosso tempo, que nos deveria inspirar, teria passado a conspirar? Não teria ele ordenado paradoxalmente o nosso tempo em quiasma? Não terá ele, como espírito, crucificado as matrizes geradoras dos vínculos, fomentando a auto-referência? 
Para compreendermos melhor essas questões e o funcionamento do espírito do nosso tempo, mas sobretudo para não sucumbirmos a ele, convém reconhecer algumas saídas:

Assim as formula Dietmar Kamper, em seu ensaio "O signo da vitória"(Kamper 1996:8-9):

"Não se pode habitar a cruz. Mas pode-se desviar da direção do gesto indicador, pode-se afastar do caminho da cruz, pode-se seguir ao lado, do letal para o transversal, para trás, para frente, se necessário para todos os lados, em queda livre. "(...)

Pois não é a cruz o signo que deve ser superado, mas é o signo a cruz da qual devemos nos afastar."

BYSTRINA, Ivan, (1989) Semiotik Der Kultur Tübingen: Stauffenburg

BÖHME, Gernot Y Hartmut, (1998) Fuego, Agua, Tierra Aire. Una Historia Cultural De Los Elementos. Barcelona: Herder

KAMPER, Dietmar, (1996) Abgang Vom Kreuz München: W. Fink

KAMPER, Dietmar, (1997) Im Souterrain Der Bilder. Die Schwarze Madonna. Bodenheim: Philo

KAMPER, Dietmar, (1999) Jan Fabre Ou L'art De L'impossible. Strassbourg: La Chaufferie

KLENK, Dominik, (1998) Gegenwartsverlust In Der Kommunikationsgesellschaft Münster: Lit 


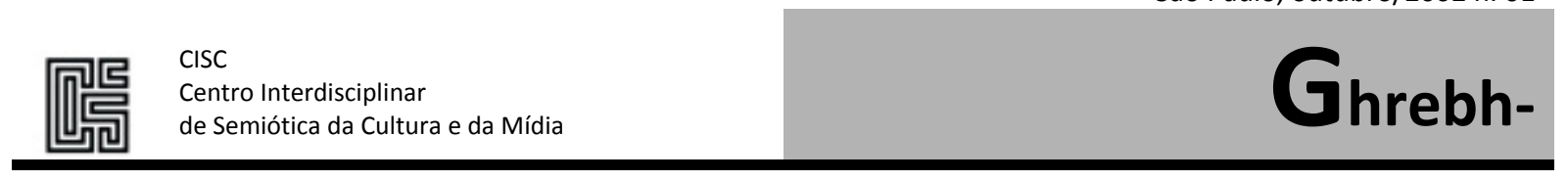

Revista de Comunicação, Cultura e Teoria da Mídia issn 1679-9100

MORIN, Edgar, (1973) O Paradigma Perdido Lisboa: Europa-America

PROSS, Harry, (1980) Estructura Simbólica Del Poder. Barcelona: G. Gili

ROTERS, Eberhard, (1990) Fabricatio Nihili Oder Die Herstellung Von Nichts. Berlin: Argon 